\title{
Sadık Rüyaların Fütürolojiye Katkısı: Sahabe Örneği
}

Ali Seyyar *

\section{Özet}

$\mathrm{Bu}$ makale, fütüroloji alanına katkı sağlayabileceği düşüncesiyle son Peygamber Hz. Muhammed'in (sav) en yakın dostları olan sahabilerin gördüğü sadık rüyalar konusunu incelemektedir. Makalede sadık rüyaların tanımı, dinî dayanağı, sahabilerin sadık rüyalar yoluyla gördükleri olayların sonraki tarihlerde gerçekleşmiş olduğu, günümüzün iyi ahlâklı insanları da sadık rüyaların muhatabı olabileceği olgusu işlenmektedir. Dolayısıyla nihaî değerlendirme çerçevesinde makalede güncel sadık rüyalar yoluyla geleceğe dair yeni bazı işaretler elde edebileceği görüşüne ve bu bağlamda sadık rüyalarla ilgili araştırma merkezleri çatısı altında bilgi bankalarının oluşturulması gerektiği önerisine de yer verilmektedir.

Anahtar kelimeler: Sahabiler; Fütüroloji; Sadık Rüyalar.

\section{The Contribution of Meaningful Dreams to Futurology: Example of Sahabi's}

\begin{abstract}
By thinking to contribute to the area of futurology this article examines the meaningful (sadik) dreams of "sahabi's" who were the nearest friends of the last Prophet Muhammed. This article obtains the subjects like the definition and the religious source of the meaningful dreams, the realisitaion of the events in the folowing dates in connecting with meaningful dreams seen by sahabi's, the fact that the meaningful dreams can be the interlocutor of today's people with a good moral. So as a final intrepretation in this article the opinion of reaching some new signs about the future by actual meaningful dreams and the offer of creation of konoledge bases under the umbrella of dream research centers are handled.
\end{abstract}

Key words: Friends of the prophet; Meaningful Dreams,

Prof. Dr., Sakarya Üniversitesi, Siyasal Bilgiler Fakültesi, Çalışma Ekonomisi ve Endüstri İlişkileri Bölümü, aseyyar@sakarya.edu.tr 


\section{Giriş}

Gelecekte gerek ferdî, gerekse içtimaî boyutta nelerin olacağını bilmek, her zaman insanoğlunun ilgi duyduğu bir husus olmuştur. Bu çerçevede rasyonel ve planlayıcı aklı ön plânda tutarak, geleceğe dair olası gelişmeler hakkında tahminî bilgiler üreten, plân ve stratejiler geliştiren "Fütüroloji” yani "Gelecek Bilim” ortaya çıkmıştır. Fütüroloji, değişik oranlarda tüm disiplinlerin verilerini kullanmak suretiyle, daha çok kurgusal (spekülatif) nitelikte, çevresel sosyo-ekonomik şartları ve insanlığın geçirdiği tarihî seyri de dikkate alarak, gelecek ile ilgili yapılan stratejik plân ve bilgiler bütünüdür. Sosyal bilimlerde fütüroloji, orta ve uzun vadede ortaya çıkabilecek demografik, kültürel, sosyo-ekonomik ve siyasî değişimleri, mevcut verilere dayanmak ve geleceğe yönelik ihtimal hesapları yapmak suretiyle kestirmeyi ve muhtemel risklere karşı tedbirler almayı öngören bir bilim dalıdır (Seyyar; 2007, s. 239).

Fütüroloji ile ilgilenen bilim insanları, çalışmalarında bilimsel bir takım yöntemleri kullandıkları halde, geleceğe dair somut ve kesin bilgi oluşturmanın hayatın karmaşıklığına bağlı olarak bazen sınırlı olduğunun da farkındadırlar. Gelecekte neyin olacağını öğrenmek ve güvenilir bilgiler ortaya koymak bu kadar güç olunca insanlar, bu meraklarını yine de giderebilmek adına başka yollara müracaat etme ihtiyaçları duymuşlardır. Mesela kendileri dışındaki bir takım varlıklardan bunu öğrenmeye çalışmışlar veya geleceğe ait tercihlerini istiharede (rüyada) gördükleri müspet veya menfi işaretlere göre belirlemişlerdir (Aydar, 2014, s. 2-4).

Bilim insanları, fütürolojik çalışmalara ve geleceğin şekillenmesine katkı sağlayabilecek meta-fizik alanların başında mahiyeti itibariyle henüz ilmî izahı yapılmış olmasa da rüyaları (sadık) görmektedir. Sadık rüyalar gibi meta-fizik (manevî) kaynaklardan elde edilen ilave işaretler tümüyle reddedilmekten ziyade ihtiyaten de olsa bunların da bir dereceye kadar değerlendirilebileceği görüşü son yıllarda kabul gördüğü için bu makalede sahabiler tarafından görülmüş geleceğe 1şı tutan sadık rüyalar üzerinde durulacaktır.

YIL: 5 SAYI: 9 


\section{1. İslâm'da Sadık Rüyaların Yeri ve Gelecekle İlişkisi}

İslâm Peygamberi Hz. Muhammed (sav), rüyaları üç kısımda değerlendirmiştir. Korkudan oluşan şeytanî rüyalar ile kişinin kendi vehimlerindenkaynaklanan rüyatürlerinden buradahiç bahsedilmeyecektir. Üçüncü kategoride olan ve manevî işaretler ihtiva edenler ise sadık rüyalardır. İşte Hz. Muhammed (sav), Allah’tan bir müjde ihtiva etmeleri hasebiyle değerlendirmeye en müsait olarak sadece sadık (salih) rüyalara atıfta bulunmuştur (Buhari, 1981; Müslim, 1981; İbni Mâce, 1981; Tirmizî, 1981; Dâremî, 1981). ${ }^{1}$

Hz. Muhammed (sav), her yönüyle iyi ve güzel olan sadık rüyaları peygamberliğin bir cüzü olarak tanımlamıştır. Bu bağlamdaki bir hadisi şerifinde, "Müminin rüyası, peygamberliğin 46 parçasından bir parçadır" beyanı önem arz etmektedir (Müslim,1981; İbn Mâce, 1981; Dâremî, 1981). Aynı konuyla ilgili diğer hadisi şeriflerde "mümin" kaydı konmaksızın, "iyi ve güzel rüya, peygamberliğin 46 cüzünden bir cüzdür”; “iyi insanın rüyası, peygamberliğin 46 cüzünden bir parçadır” (Müslim, 1981; İbn Mâce, 1981) demiştir.

Sadık rüyaların bir kısmı, geleceğe dönük önemli işaretler barındırabilmektedir. Hz. Muhammed'e (sav) inen vahyin ilk olarak sadık rüyalar şeklinde gelmiş ve bu rüyalar, er veya geç aynen gerçekleşmiştir (Buhari, 1981).

Kuran, genelde peygamberlerin, özelde Hz. Muhammed'in (sav) gördüğü sadik rüyalar hakkında bilgi vermektedir. Mesela "Andolsun Allah resulünün rüyasını doğru çıkardı. Allah'ın dilemesiyle (kiminiz) başlarını tıraş etmiş olarak, (kiminiz de) saçlarını kısaltarak korkmadan, güven içinde Mescid-i Haram'a gireceksiniz..."2 âyeti, açıkça geleceğe işaret eden sadık bir rüyaya atıfta bulunmaktadır. Bu âyetin ifadesinden anlıyoruz ki Allah, Peygamber'inin (sav), Müslümanların Mekke'ye gireceklerine dair daha önce gördügü rüyayı doğru çıkarmış ve Müslümanlar, rüyada görüldüğü üzere saçlarını tıraş etmiş oldukları halde güven içinde Mekke'ye girmişlerdir (Zemahşerî, 1995; İbni Kesir, t.y.; an-Nasafî, 1984).

1 Bunlarla ilgili açıklamalar için bkz. Ahmed b. Ali İbn Hacer el-Askalânî; 1987; XII: 370-371; 379-391.

2 Kuran; Fetih (48): 27'de bu konu dile getirilmiştir. 


\section{$116 \cdot$ YALOVA SOSYAL BILIMLER DERGISI}

Sadık rüyalar görmek, sadece Peygamberlere mahsus bir hususiyet değildir. Başta sahabiler olmak üzere Peygamberlerin yolundan giden veya iyi ahlâk sahibi olan bütün Müslümanlar, geleceğe yön veren güzel ve anlamlı rüyalar görebilir. Nitekim son hastalığı sırasında "Ümmetime nübüvvetten sonra sadece mübeşşirat (müjdeleyiciler) kalmıştır" diyen Hz. Peygamber (sav), mübeşşiratı ahir zaman müminlerin görebileceği sadık (salih) rüyalar olarak beyan etmiştir (Buhari, 1981; Müslim, 1981; Tırmizî, 1981; İbni Mace, 1981). Vahiy son bulmuştur ama Hz. Peygamberin (sav) ifadesi ile "Ahir zamanda müminlerin rüyaları yalan çıkmaz çünkü müminlerin rüyaları, nübüvvetin kırk altı cüzünden biridir.” (Buhari, 1981; Müslim, 1981). Bu bağlamda bir keresinde sahabi Hz. Ebu Derda'ya "Dünya hayatında müjde onlara..."3 âyet-i kerimesi sorulduğunda o, şöyle cevap vermişti: “Bunu Hz. Peygamber'e (sav) sorduğumdan beri kimse bana bunu sormamıştı. Bu, bir Müslümanın gördüğü veya onun hakkında görülen sadık rüyadır. Bu dünya ve ahiret hayatı için bir müjdedir." (Tirmizi, 1981; Dimaşki, 2006).

\section{Sahabilerin Gelecekle İlgili Gördükleri Sadık Rüyalar}

Nasıl ki Hz. Peygamberin (sav) gördüğü rüyaların bir kısmı ileriye dönük mesajlar içermiş ve vahiy özelliği taşıması hasebiyle kesin olarak gerçekleşmiş ise sahabilerin gördüğü bazı sadık rüyalar da Hz. Peygamberin (sav) işaret ettiği mübeşşirat kapsamında değerlendirebileceği için geleceğe dönük olmuş ve bunların bir kısmı da gerçekleşmiştir. Hz. Peygamber (sav) döneminde yaşamış olan sahabiler böyle anlamlı rüyalarını ona anlatmışlar ve o da bunları her zaman müspet bir şekilde tabir etmiştir. Ayrıca rüya sahiplerine, gördükleri rüyalar karşısında nasıl davranmaları gerektiği konusunda da bilgi vermiştir. Örnek teşkil etmesi bakımından geleceğe 1ş1k tutmuş olan dokuz sahabe rüyası, burada kısa değerlendirmeleriyle birlikte ele alınacaktır.

\subsection{Hz. Ebu Bekir: Hz. Muhammed'in (sav) Peygamber Olacağını Görmesi}

Hz. Ebu Bekir, bir Şam seferinde, rüyasında Ay’ın gökten inip kucağına girdiğini görür. Ayı eliyle tutup bağrına basar. Uyanınca Yemliha

3 Kuran; Yunus (10): 64'de bu konu dile getirilmiştir.

YIL: 5 SAYI: 9 
adında bir rahibe gidip rüyasını yorumlatır. Rahip, bazı bilgiler edindikten sonra şöyle tabir eder: "Gökten inen Ay, ahir zaman peygamberidir ki, yakınlarda zuhur edecektir ve sen onun hayatında veziri, sonrada halifesi olacaksın. Ben sağken sen ona yetişirsen, bana haber gönder ki, onun yanına ben de geleyim. Şayet dünyadan gitmiş bulunursam, ona selamımı söyle ve onun dinine girdiğimi ve onun ümmetinden olduğumu ve ahirette beni şefaatinden mahrum etmemesini söyle."

Aradan on iki yıl geçer. Hz. Muhammed'e (sav) ilk vahiy geldiği zaman Hz. Ebu Bekir, yine ticaret maksadiyla Yemen'de bulunmaktaydı. Bu haberi alır almaz Hz. Ebu Bekir hemen Hz. Muhammed'in (sav) yanına gider ve sorar: "Ey Ebû Kâsım! Peygamberlik iddiasında bulunduğun doğru mu?" "Evet, ey Ebû Bekir! Ben, sana ve bütün insanlara âlemlerin Rabb'i tarafından gönderilmiş bir elçiyim. İnsanları bir ve tek olan Allah'a inanmaya, putlara tapmaktan vazgeçmeye çağırıyorum.” Hz. Ebu Bekir, "Peygamber olduğuna dair delilin nedir? der. Resul-ü Ekrem (sav), şöyle cevap verir: "Sana o delil yetmez mi ki, on iki sene evvel bir rüya görüp, Yemliha adlı rahibe tabir ettirdin ve on iki altın verdin ve yüz altın daha vaatte bulundun ve $O$, on iki satırlık mektup yazıp bana vermek üzere sana verdi." (İbn Kesir, t.y.).

Gördüğü çok anlamlı rüya sonrasında Hz. Ebu Bekir'in sergilemiş olduğu tutum ve davranışları Hz. Muhammed'in (sav) söylediği gibi aynen vuku bulmuştu. Üstelik yillar öncesinden tabir edildiği gibi rüya, Hz. Muhammed'in (sav) peygamber oluşu ile gerçekleşmiş de oldu. Hz. Ebu Bekir, rüyanın doğruluğunun ve Hz. Muhammed'in (sav) Allah ve kendisinden başka kimsenin bilemeyeceği geçmişe ait ayrıntılı tespitlerin etkisiyle kelime-i şehadet getirdi ve ilk Müslümanlardan oldu.

Şüphesiz sadece bu rüya, Hz. Ebu Bekir'in Müslüman olmasını izah etmez. Hz. Peygamber'in (sav) toplum tarafindan sevilip sayılmas1, buna bağlı olarak el-emin vasfı taşıması, güzel ahlâklı olması ve vahiy doğrultusundaki etkileyici mesajlar vermesi gibi özellikler, Hz. Ebu Bekir'in Müslüman olmasına sebep olmuştur. Ancak bu sadık rüya da elbette Hz. Ebu Bekir'in iman etmesini kolaylaştırmıştır diyebiliriz. 


\section{$118 \cdot$ YALOVA SOSYAL BILIMLER DERGISI}

\subsection{Hz. Âtike Binti Abdulmuttalib: Mekke Müşriklerini Korkutacak Bir Rüya Görmesi}

Hz. Âtike rüyasında, devesinin üzerinde Mekkeıye gelen ve yüksek sesle savaşa çağıran bir adam görmüştü. Adam: "Ey Topluluk! Haydi savaş için hazırlanıp üç güne kadar sefere çıkın! Çıkın ki başınıza gelecek gadri ve devrileceğiniz yeri kendiniz görün” diyordu. Bir anda, etrafında büyük bir kalabalık toplanıvermişti. Ardından aynı adam, Kâbe'ye geldi; insanlar da onu takip ediyorlardı... Sonra yerden büyükçe bir kayayı söküp aldı ve onu, Ebû Kubeys dağından aşağı doğru firlattı. Kaya, bir anda paramparça oluvermişti. Sonra bu kayadan ayrılan her bir parça büyük bir gürültüyle Mekke evlerinden mutlaka birine isabet etmiş ve içine girmişti... (Dimaşki,2006).

Bu rüya, kısa zamanda her tarafa yayıldı. Her ne kadar bu rüyayı yalanlamak mecburiyetinde kaldılar ise de başta Ebu Cehil olmak üzere bütün Mekkeli müşrikler, korku ve paniğe kapıldılar. Çünkü rüyanın gerçek olmasından endişe ediyorlardı.

Hz. Âtike'nin rüyasının üçüncü gününde devesinin üzerinde Mekke'ye doğru Damdam İbn Amr isminde bir müşrik, büyük bir heyecanla bağıra bağıra gelir. Bu adam, Ebu Süfyan tarafindan 20 miskal altına kiralanan birisiydi. Görevi, Mekkelilere Kureyşlilerin ticaret kervanını ele geçirmek üzere olan Müslümanların bu girişimiyle ilgili bilgileri derhal ulaştırmak ve sefere çağırmaktı. Adam, "Ey Kureyş topluluğu! Felaket var, felaket! Ebu Sufyan'ın gözetiminde Şam〉a gönderdiğiniz mallarınıza Muhammed ve ashabı el koydu! Ona yetişebileceğinizi ve mallarınızı kurtarabilceğinizi sanmıyorum. Üç güne kadar, muharebe mahalline, vurulup düşeceğiniz yerlere yetişiniz! İmdat! İmdat!” diye bağırıyordu. Tıpkı Hz. Âtike`nin rüyasında olduğu gibi bu adam da, bu mesajı üç kez haykırmıştı.

Böylece Bedir savaşına sebep teşkil eden Ebû Süfyan'ın kervanının Müslümanlar tarafından baskına uğradığı haberi, üç gün önce Hz. Âtike tarafından görülen rüyanın sadık (doğru) olduğunu göstermişti. İşte bu rüya, müşrikler için bir felaket, Müslümanlar için ise bir müjde niteliği taşımaktaydı.

YIL: 5 SAYI: 9 


\subsection{Hz. Ümmü'l-Fadl Lübâbe Binti El-Hâris: Hz. Hüseyin'in Süt Annesi Olacağını Görmesi}

Hz. Ümmü Haris, bir gün etrafında sahabiler varken Allah'ın Resulü'nün (sav) huzuruna girer ve O'na (sav) heyecanla der ki: 'Ey Allah'ın Resulü; Bu gece bir rüya gördüm. Hala tesirindeyim. Tabir eder misin?" Hz. Peygamber (sav), ona ne gördüğünü sorar ve Hz. Ümmü Haris, rüyasını gördüğü gibi O’na (sav) anlatır: "Rüyamda sizi gördüm! Bilahare dehşetli bir şeyler oluyor. Muhterem vücudunuzdan bir parçayı kesiyor ve daha sonra getirip benim yan tarafıma dikiyorlar. Ben buna bir mana veremedim." Hz. Muhammed (sav), şöyle buyurdu: "Hiç üzülme! Bunda müjde vardır. İyi görmüşsün. Fatıma'nın bir oğlu olacak ve senin yanında kalıp büyüyecektir. Bu rüya ona işarettir.” Rüyayı gören Hz. Ümmü'lFadl, bir süre sonra, Hz. Peygamber'in (sav) kızı Fatıma'nın Hz Hüseyin'i dünyaya getirdiğini ve kendisinin de onu bir süre emzirdiğini anlatmıştır. Dolayısıyla Hz. Muhammed'in teyit ve tabirleriyle bir bayan sahabi tarafından görülen bu müjdeliyici rüya, gelecek hakkında özel bilgiler sunan sadık bir rüya idi (İbn Mace, 1981).

\subsection{Hz. Abdullah bin Amr: İki İlahî Kitap Okuyacağını Görmesi}

Hz. Abdullah bin Amr, bir gün rüyasında sanki parmaklarından birinde bal, diğerinde yağ bulunduğunu ve başka bir parmağıyla da onları yaladığını görür. Hz. Abdullah, bu rüyasını Hz. Peygambere (sav) anlatır. Hz. Muhammed (sav), bu rüyayı şöyle tabir eder: "Eğer yaşarsan iki kitabı da, yani Tevrat ve Kuran'1 okuyacaksın.” Gerçekten Hz. Abdullah, çok geçmedi yabancı dillere hâkim olan sayılı bilge sahabilerden oldu. Süryanice ve İbranice lisanlarını gayet iyi anlayabilecek konuma geldi. $\mathrm{Ku}$ ran'ın yanında İbranice olan Tevrat'ı da rahatlıkla okuyup anlayabiliyordu (Dimaşki, 2006, s. 323).

Sembolik emareler taşıyan bu türdeki sadık rüyaların, rüya sahibinin şahsî özellikleri doğrultusunda doğru, yani kişiye fayda sağlayabilecek türde tabir edilmesi halinde, yukarıdaki örnekte görüldüğ̈ gibi gelecekte aynen vuku bulması söz konusu olabilmektedir. 


\subsection{Hz. Abdullah İbni Mesud: Ebu Cehil’i Öldüreceğini Görmesi}

Bir keresinde Ebu Cehil, küçümsediği Hz. İbni Mes'ud'a şunları söylemişti: "Seni birgün mutlaka öldüreceğim.” Buna karşılık Hz. İbni Mes'ud da hiç çekinmeden ona şöyle cevap vermişti: "Vallahi, seni geçenlerde rüyamda gördüm. Rüyamda (olgunlaşmamış) kabak bir karpuzu alıp ayakkabılarımla senin iki omuzun arasına koyduğumu gördüm. Eğer bu doğru çıkarsa, kesinlikle ayaklarımla boynuna basıp bir koyunu boğazlar gibi seni boğazlayacağım."

Bu sözler karşısında Ebu Cehil, tedirgin olmuş ve Hz. İbni Mesud'a daha fazla ilişmemiş. Bu rüya ile ilgili olarak İslâm'ın ilk savaşı olma özelliğine haiz Bedir Muharebesindeki olaylar hakkında kısa bir bilgi vermek gerekirse. Bu savaşta Ebu Cehil, Hz. Muaz bin Amr ve Hz. Muaz bin Haris tarafından etkisiz hâle getirilmişti. Hz. İbn-i Mes'ud, Ebu Cehil'i son nefesini vermek üzere iken bir yerde bulmuş, o esnada rüyasını hatırlamış ve gördüğü rüyayı gerçekleştirmek için ayağını Ebu Cehil'in boynuna koymuştur. Rüyada gösterildiği gibi Ebu Cehil'in kellesini kesmek, Hz. İbni Mesud'a nasip olmuştu. Vücudunun zayıflığı yüzünden, kelleyi ancak sırtına alarak, Hz. Muhammed'e (sav) getirebilmişti. Ebu Cehil'in başı kesilip huzura getirilince, Hz. Muhammed (sav) şöyle buyurmuştur: "Her ümmetin bir Firavunu vardır. Bu ümmetin Firavunu da Ebu Cehil'dir. Allah, onu en kötü biçimde öldürmüştür. Onu Afra'nın iki oğlu öldürmüştür. Onu melekler öldürmüştür. İbni Mesud da tepesine çıkıp işini bitirmiştir.”4

\subsection{Hz. Ali: Şehit Edileceğini Görmesi}

Hz. Ali, Hicri 40. yılın Ramazan ayının 27. gecesinde rüyasında Hz. Peygamberi (sav) görür. Rüyasında Hz. Muhammed (sav), ümmetinden şikâyetçi olduğu için, Hz. Ali'den onların aleyhine dua etmesini ister. Hz. Ali, bunun üzerine şöyle dua eder: "Ya Rabbi! Bana onlardan hayırlısını ver, onlara da benden fenasını ver." Uykudan uyanır uyanmaz Hz. Ali, oğlu Hz. Hasan'a rüyasını anlatır. Bu esnada sabah ezanı okunmaya başlar. Hz. Ali, mescide yöneldiği sırada avludaki ördekler, onun üzeri-

4 Dimaşkî; C. IV: 83-86. Bkz. ayrıca: Buhari; VI: 283. Müslim; C. III: 1372 (1742-1752).

Beyhakî; Delail; C. III: 90. İbn ebî Şeybe; el-Musannaf; C. XI: 59.

YIL: 5 SAYI: 9 
ne çağrışmakla yanındakiler, onları kovalamak isterler. Hz. Ali, müdahale eder ve şöyle der: "Onlara dokunmayınız. Onlar nevahiydir (ölü üzerine ağlayıcılardır).” Hz. Ali, sabah namazını cemaatle kıldıktan sonra camiden çıkmak üzereyken İbni Mülcem isimli gözü dönmüş bir harici, aniden zehirli kılıcı ile Hz. Ali'nin başının ön tarafına vurur ve nihayetinde şehit olmasına sebebiyet verir (Güven-Belbağı, 2006, s. 238).

\subsection{Hz. Muhriz bin Nadle: Şehit Edileceğini Görmesi}

Hz. Muhriz, rüyasını şöyle anlatır. "Rüyamda gökyüzünün benim için açıldığını ve dünya semasından içeri girdiğimi gördüm. Sonunda yedinci kat semaya kadar yükseldim. Oradan da Sidretü'l-münteha'ya çıktım. Sidretü'l-münteha'da bana denildi ki: 'Burası senin makamındır.' Daha sonra rüyamı Ebu Bekir'e anlattım. Ebu Bekir, insanların en iyi rüya tabircisi idi. Bana 'Müjde' Sen şehit olacaksın!' dedi.” (Dimaşki,2006,s.133). Gerçekten bir gün sonra Hz. Muhriz'in de içinde bulunduğu bir mücahit birliğine, Müslümanların mallarına zarar veren bir eşkıyayı takip etmek üzere görev verilir. Bu rüyanın etkisiyle kendi başına cesaretle eşkıya takımının saklandığı yere kadar ilerleyen Hz. Muhriz, çetin bir mücadeleden sonra çok arzuladığı şehitlik makamına ulaşır.

\subsection{Hz. Tufeyl bin Amr: Kendisinin ve Oğlunun Şehit Olacağını Görmesi}

Halife Hz. Ebu Bekir'in talimatıyla Hz. Tufeyl, oğlu Hz. Amr de aralarında olmak üzere bir grup Müslümanla sefere çıkar ve mürtetlerin işini bitirir. Sonra Yemame'ye hareket eder. Bu yolculuk esnasında gördüğü bir rüyayı yanında bulunan Müslümanlara şu şekilde anlatır: "Bir rüya gördüm, tabir ediniz bakalım. Başımın tıraş edildiğini, ağzımdan bir kuş çıktığını ve benimle karşılaşan bir kadının beni fercine soktuğunu gördüm. Oğlum, her yerde beni arıyordu, ama bana kavuşamadı." Rüyasını dinlemiş olanlar, "Hayır gördün inşallah" derler ve tabir etmekten çekinirler. Hz. Tufeyl, "Vallahi, ben tabir ettim bile" diyerek rüyasını şu şekilde yorumlamaya başlar: "Başımın tıraş edilmesi, kopması demektir. Ağzımdan 


\section{$122 \cdot$ YALOVA SOSYAL BILIMLER DERGISI}

çıkan kuşa gelince o, benim ruhumdur. Beni fercine sokan kadın ise kazılacak topraktır. Ben defnedilip orada kaybolacağım. Oğlumun beni arayıp bulamaması, kanaatime göre benim şehit olduğum gibi, o da şehit olmak için çabalayacak.”(Dimaşki, 2006, s. 285).

Hakikaten Hz. Tufeyl, Yemame Harbinde yalancı peygamber Müseylime-i Kezzap'ın adamlarıyla savaşırken şehit olur. Oğlu Hz. Amr ise orada aldığı ağır bir darbe sonunda sağ kolunu kaybeder. Hz. Amr, buna rağmen savaşlara katılmaya devam eder ve Yermuk Savaşı'nda o da babaS1 gibi şehit olur (Seyyar, 2013).

\subsection{Hz. Zürare bin Amr: Doğmuş Olan Çocuğunu ve Fitne Dönemlerini Görmesi}

Yemen'den biat etmek üzere Medine'ye yola çıkan Naha heyetinin ileri gelenlerinden olan $\mathrm{Hz}$. Zürare bin Amr, yolculuk esnasında korku dolu bir rüya görür. Hz. Muhammed'le (sav) Medine'de buluştuğunda aralarında şöyle bir sohbet geçer:( İbn Kayyım, t.y.; İbn Hacer, 1987; Dimaşki, 2006, s. 368) Hz. Zürare: "Ya Resulullah! Bir rüya gördüm. Evimde bırakmış olduğum dişi merkep, çil, kara kızıl bir oğlak doğurmuş! Yerde, bir ateşin çıkıp benimle oğlumun arasına gerildiğini de gördüm ki; o ateş, 'Dumanlı ateş! Dumanlı ateş! Gözlüsü, gözsüzü! Bana yiyecek yediriniz! Ben sizin ev halkınızı ve malınızı yerim!' diyordu."

Hz. Peygamber (sav): "Sen evinde hamile, gizli bir cariye biraktın mı?" diye sorar. Olumlu bir cevap alan Hz. Peygamber (sav): "İște o cariye bir oğlan doğurmuştur. O, senin oğlundur” buyurur. Hz. Zürare: "Ben onun çil, kara kızıl olmasının sebebini anlayamadım?" der. Hz. Peygamber (sav): "Yakınıma gel!" buyurur ve "Sende gizli tutup kimseye açıklamadığın bir bars (alaca hastalığı) var mı?" diye sorar. Bunun üzerine Hz. Zürare: "Seni hak peygamber olarak gönderen Allah'a yemin ederim ki; onu senden önce hiç kimse bilmiyordu!" der. Hz. Peygamber (sav): "İşte, rüyada gördüğün çil, kara kızıllık odur!” der.

Daha sonra "Gördüğün ateşe gelince; o, benden sonra kopacak fitnedir! O, ahir zamanda kopacaktır!” buyurur. Hz. Zürare: "Ya Rasulallah! 
Kopacak fitne nedir?" diye sorar. Hz. Peygamber (sav): "Müminlerin kanını dökmek, mümine baldan, sudan tatlı gelecek! Kötülük yapan, kendine iyilik yapıyor sanacaktır! Sen ölürsen, bu hâli oğlun görecektir. Oğlun senden önce ölürse, sen göreceksin!" buyurur. Hz. Zürare: "Ya Resulallah! Allah'a dua et de, onu ben görmeyeyim!” der. Hz. Peygamber (sav): “Allah'ım! O fitneyi buna gösterme!” diyerek dua eder. Hz. Zürare, oğlundan önce vefat eder, fitne dönemlerini görmez, ancak oğlu Hz. Osman'ı halifelikten indirenlerin arasında yer alır.

\section{Sonuç}

Yukarıdaki örneklerden de görüldüğü üzere sadık rüyalar, bazı sırların keşfine ve bazı mahrem işaretlerin elde edilmesine yardımcı olan kuvvetli bir manevî kaynak hükmündedir. Peygamberliğin sona ermesinin ardından, insanlara (geleceğe ait) doğru ve güzel haberler veren "müjdeleyiciler", sadık rüyalar yoluyla devam edeceğini bizzat Hz. Muhammed (sav) beyan etmiştir. Hz. Muhammed (sav), peygamberlik ile sadık rüya arasında pozitif bir ilişki kurarak, salih bir insanın gördügü sadık rüyanın doğruluğuna işaretle, "peygamberlikten olan, yalan olmaz” ifadesi (Buhari, 1981), bilim insanlarının sadık rüyalar üzerinde araştırma yapmasını adeta teşvik eder mahiyettedir. Amel-i salihte bulunan yani hayırlı işler yapan Müslümanların gördükleri-görecekleri sadık rüyaların ilmî değeri ve bilgi kaynağı olup olmadığı noktasında zahirî bilim erbabıyla mutasavvıflar arasında her zaman bazı tartışmalar yaşanmıştır. Kanaatimce özellikle sosyal hayatımıza dair bilimsel çalışmalarda aklî ve deneysel yöntemlerin yanında ihtiyatlı da olsa sadık rüyalara dayanan bireysel tecrübelerden de yararlanmakta fayda vardir. ${ }^{5}$

Batı dünyasında rüya türleri ve kişiler üzerindeki yansımaları üzerinde yapılan bilimsel çalışmalar ve buna bağlı olarak tertiplenen sayısız sempozyumlar dikkate alındığında Müslüman bilim insanları (ilahiyatçılar) da bu alana önemli katkı sağlayabilecek konumdadırlar.

5 İlahiyatçı Enbiya Yıldırım da İslâm âlimi Beyhakînin görüşleri doğrultusunda muhaddislerin, aklî yöntemlere ilaveten sadık rüyaları da kullanmaları, ulemanın birbirlerine yakınlaşmasını sağlayıcını ifade etmektedir. Bu konudaki görüşler hakkında bkz. Yıldırım; 1998; s. 181. 


\section{$124 \cdot$ YALOVA SOSYAL BILIMLER DERGISI}

Ancak günümüzün Müslüman bilim insanlarının, bazı endişe ve kaygılarından dolayı (sadık) rüyalara gereken önemi vermemeleri ve bu alan ile ilgili yeterince ilmî ve deneysel çalışmalar yapmamaları, genel anlamda hem rüya araştırmaları, hem de fütürolojinin gelişimi açısından önemli bir kayıptır. Diğer taraftan birçok Müslüman, gördüğü sadık rüyaların mahiyetini çoğu zaman kendi başına değerlendirebilecek konumda olmadığ için, bu alanda önemli bir kaynak kaybı yaşanmaktadır.

Halbuki rüyaları tabir etmek, Hz. Peygamber'in (sav) uygulamalarında da görüldüğü üzere, İslâm dini teşvik etmektedir. Ancak rüyaların doğru ve isabetli tabiri için, bu alanda gerek deskriptif (kitabî), gerekse tecrübî birikime sahip ehil insanlara ihtiyaç vardır. Sadık rüya sahibi Müslümanlar, rüyalarını genelde ne güvenebildikleri ehil insanlara, ne de bunun için oluşturulmuş yetkili mercilere iletebilmektedir. Bir başka ifadeyle Türkiye'de Kuran ve Sünnete uygun olarak rüya tabirciliği yapabilecek seviyede olan ne yeterli sayıda ehil insan, ne de nitelikli bir kurumsal yapı mevcuttur.

Müslümanlar, anlamlı ve(ya) gizemli buldukları rüyalarını bunun için kurulmuş ilmî merkezlere iletemedikleri için, rüya araştırmalarında önemli bir gelişme kaydedilmediği gibi, bu boşluktan yararlanan şarlatanlar da bu konuyu kolaylıkla istismar edebilmektedir. Bunun için Diyanet ve(ya) İlahiyat Fakülteleri çatısı altında Kuran ve Sünnete uygun araştırma yapacak rüya merkezleri oluşturulmalı ve bu çalışmalar sayesinde zamanla yeterli sayıda rüya uzmanları yetiştirilmelidir. Bunun için pratikte sadık rüya görebilen veya görmüş olan Müslümanların bilgi ve tecrübelerinden bir ekip ruhu anlayışı doğrultusunda yararlanmalıdır.

Görülen sadık rüyalar, Rüya Ar-Ge Merkezlerinde oluşturulacak bilgi bankalarında belirli kıstaslara göre toplanmalı ve tasnif edilmeli, kıyaslanabilir hâle getirilmeli, ampirik araştırmalar doğrultusunda fütürolojik nitelikte olanlar spesifik olarak değerlendirilmeli, rüya sahiplerine bireysel danışmanlık hizmetleri çerçevesinde tabirde bulunulmalı, önemine ve aciliyetine binaen gerekli tedbirler alınmalıdır. Stratejik çalışmalar doğrultusunda en nihayetinde sadık rüya gibi zengin bir manevî kaynaktan ulusal boyutta geniş bir ilmî hazine/havuz oluşturulmalı ve ortaya çıkan değerlendirilebilir veriler, tasnifsel içeriğine göre potansiyel katkı unsuru olarak fütüroloji dâhil değişik bilim dallarının hizmetine sunulmalıdır. 
KAYNAKLAR

Aydar; H. (2014).“'̇stihare ve Rüya: Rüya Yolu ile Geleceği Önceden Öğrenme Girişimi”; www.sosyalargem.com; Erişim: 12.07.2014.

Beyhakî (Ahmed bin Hüseyin Beyhakî). (1985). Delâilü'n-Nübüvve ve Şuâbü'lImân; Beyrut.

Buhârî (Muhammed bin İsmail el-Buhari) .(1981). Sahih el-Buhari-Kitâbu'tTa 'bîr; Çağrı Yayınları; İstanbul.

Daremî (Ebû Muhammed Abdullah ed-Dâremî) .(1981). Sünenu'd-Dâremî; Çağrı Yayınları; İstanbul.

Dimaşkî (Muhammed bin Salih ed-Dimaşkî). (2006). Peygamber Külliyatı (Daru'l-Kutubi'1-İlmiye-Beyrut-Lübnan-1993); C. I-XII; 2. Bask1; Ocak Yayınc1lık; İstanbul.

En-Nesafî-Abû al-Barakât Abdullah b. Ahmad al-Nasafî. (1984). Tefsîr el-Nasafì (Madârik al-Tanzîl ve Hakaik el-Te’vîl); Kahraman Yayınları; İstanbul.

Güven, M. Yusuf ve Belbağı, Osman Fatih. (2006). Hakikat Penceresi mi? Hayal Perdesi mi? Rüya, Gül Yurdu Yayınları; İstanbul.

İbn ebi Şeybe (Ebu Bekr Abdullah b. Muhammed b. İbrahim). (2004). ElMusannaf; I-XVI, Mektebetü'r-Rüşd, Riyâd.

İbn Hacer el-Askalânî; Fethu'l-Bârî bi Şerhi Sahîhi'l-Buhârî; (Tarkim, tahriç ve tashih: M.F. Abdulbâkî - M. El-Hatîb). (1987). Dâru'r-Reyyân li'tTurâs; Kâhire.

İbni Kayyım. (t.y.). Zâdu'l-mead; Cantaş Yayınları; İstanbul.

İbni Kesir. (t.y.). el-Bidaye ve en-Nihaye; Matkaba el-Maarif; Beyrut.

İbni Mâce (Ebu Abdullah Muhammed İbni Mâce). (1981). Sünen İbni MâceKitâbu Ta 'bîri'r-Ru'yâ; Çağrı Yayınları; İstanbul.

Kuran-Kerim.

Müslim. (1981). Sahih Müslim-Kitâbu'r-Ru'yâ; Çağrı Yayınları; İstanbul. 


\section{$126 \cdot$ YALOVA SOSYAL BILIMLER DERGISI}

Rûdanî (Muhammed bin Süleyman er-Rûdanî). (2008). Cem'ul-Fevaid min Cami'il-usul ve Mecmua'iz-zevaid; (terc.: Hüseyin Yıldı); C. I-VIII; Ocak Yayınc1lık; İstanbul.

Seyyar, Ali. (2007). İnsan ve Toplum Bilimleri Terimleri (Ansiklopedik Sosyal Bilimler Sözlüğ̈̈); Değişim Yayınları; Sakarya.

Seyyar, Ali. (2013). Yıldızlar Engel Tanımaz-Bedensel Özürlü Sahâbîlerin Hayatı: Hz. Amr bin Tufeyl; IV. Baskı; Rağbet Yayınları; İstanbul.

T1rmızî. (1981). Sünenu 't-Tirmizî; Çağrı Yayınları; İstanbul.

Yıldırım, E. (1998). "Beyhakî ve Hadis Rivâyetinde Rüyaya Verdiği Değer" Cumhuriyet Üniversitesi Ilahiyat Fakültesi Dergisi; Sivas; C. V, Sayı: 1.

Zemahşerî- Ebu el-Kâsım Cerallah Mahmud bin Ömer el-Zemahşerî (1995). Tefsir 'ül-Keşşaf...; Dâr el-Kutub el-İlmiyye; Beyrut. 